\title{
The sea star igkappa gene and its applications in cancerology
}

\author{
Abstract \\ It was shown 32 years ago that the sea star axial organ cells (AO cells) produced a \\ spontaneous cytotoxicity against mouse cancerous cells. Recently, we discovered a sea star \\ Igkappa gene with immune properties. This gene was inserted in a CMV (cytomegalovirus) \\ and finally in a plasmid called « young " plasmid. The induced « young " protein exerted a \\ spontaneous cytotoxicity against osteosarcom cells (U2oS cells) and recently against Hela \\ cells (cervix carcinoma cells).
}

Volume 5 Issue 4 - 2017

\section{Michel Leclerc}

Doctor es Sciences University of Orléans, 556 rue Isabelle Rome, 45640 Sandillon, France

Correspondence: Michel Leclerc, Doctor es Sciences University of Orléans, 556 rue Isabelle Rome, 45640 Sandillon, France,Email mleclerc45@gmail.com

Received: January 0I, 1970 | Published: April II, 2017

\section{Introduction}

In 1983, Luquet and Leclerc ${ }^{1}$ shown that the axial organ cells (AO cells), exerted a spontaneous and induced cytotoxicity against mouse SP2 myeloma cells and MBL2 cells. The AO cells included essentially lymphocytes and phagocytes ${ }^{1} 30$ years later; we discovered a sea star Igkappa gene ${ }^{2}$, with immune properties. ${ }^{3}$. The aim of the present work was to study the behaviour of the « young " protein secreted by the sea star Igkappa gene, an anti HRP protein, in front of human malignant (U2oS, Hela cells) and healthy cells (human dendritic cells), by the use of plasmids.

\section{Materials and methods}

Gene cloning in a cytomegalovirus (CMV) was done in Germany (Euro fins Genomics) (Figure 1,2), from the sea star Igkappa gene, ${ }^{2}$ an anti-HRP gene. It constitutes the "promoter». We recall the importance of anti-HRP epitopes synthesis and their relevance in Invertebrates. ${ }^{3}$ Following steps as plasmid realization in correlation with the promoter, plasmid amplifications, transfections ${ }^{4}$ were performed in the laboratory of DR S. Ruchaud ${ }^{\circ}$ (CNRS, FRANCE) and Pr; C.Pichon ${ }^{\circ}$ (CNRS, FRANCE) U2oS human cells, Hela human cells (cervix carcinoma cells) Dendritic cells as controls were used. They were transfected by plasmids, after electroporation, at time $\mathrm{t}=0$. They were observed at $\mathrm{t}=24 \mathrm{~h}$ at $\mathrm{t}=48 \mathrm{~h}$ : reactions were blocked to be estimated in western blots, as already described. ${ }^{5}$

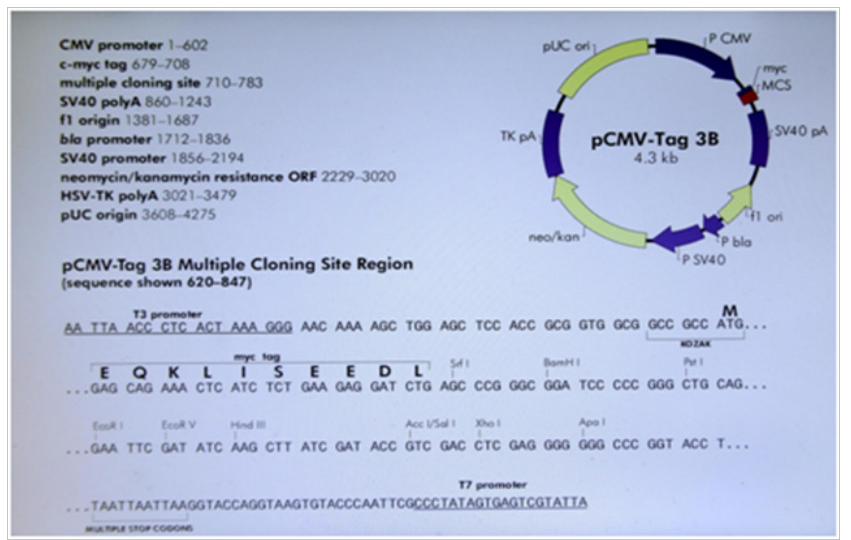

Figures 1,2 The PCMV-Tag 3B.

\section{Results}

The protein « young », also named: invertebrate primitive antibody seem to exert a spontaneous cytotoxicity 24 hours after transfection against osteosarcom cells (U2oS cells) against Hela cancerous cells (48 hours after transfection: 50-60\%cytolysis). Western blots do not confirm, in the present time, at the level of transfected cells, the protein expression, for unknown reasons. But we estimated that the protein anti-HRP may be present in the supernatant of transfected cells. Further experiment is necessary to valid this hypothesis. From another point of view, the young protein exerts also a weaker spontaneous cytotoxicity (30\%cytolysis) against dendritic cells used as controls.

\section{Conclusion}

These results have proven to be of particular importance and could open the way to immune field in human cancer therapy. It is a preliminary work and we attempt, now, to test other lineages of human malignant cells and healthy cells. About these last ones, we suggest to use another lineage of human control cells because dendritic cells are implicated in immune response (Antigen presentation) in man and sea star Igkappa gene and young protein belong to the sea star primitive antibody. So, the possible interaction between this type of cells and a primitive antibody could be problematic. The cytolysis of human cancerous cells by the " young protein » would be spectacular if we could spread this property to other types of human cancerous cells, as it was shown for mouse malignant cells ${ }^{1}$ with $\mathrm{AO}$ cells.

\section{Acknowledgments}

None.

\section{Conflicts of interest}

The authors declare no conflicts of interest.

\section{References}

1. Luquet G, M.Leclerc. The sea star Igkappa gene :effects against human cancerous cells. Immunol Lett. 1983;6:107-108.

2. Vincent $N$, Osteras $M$, Otten $P$, et al. A new gene in A. rubens:A sea star Ig kappa gene. Metagene. 2014;2:320-322.

3. Leclerc M, P Otten SAJ. Immune Properties Corroborated by A. Rubens Sea Star Igkappa Gene. Biotechnology. 2014;1:104. 
4. Paschinger K. Revealing the Anti-Hrp Epitope in Drosophila and Caenorhabditis. Glycoconj J.. 2008;26(3):385-395.
5. I-Fen Chen, Ou-Yang F, Hung JY, et al. AIM2 suppresses human breast cancer cell proliferation in vitro and mammary tumor growth in a mouse model. Mol Cancer Ther. 2006;5(1):1-7. 